\title{
Posterior mandibular rotations
}

\author{
Julia COHEN-LEVY, Sophie ROZENCWEIG \\ With the gracious participation \\ of Professor Jean DELAIRE
}

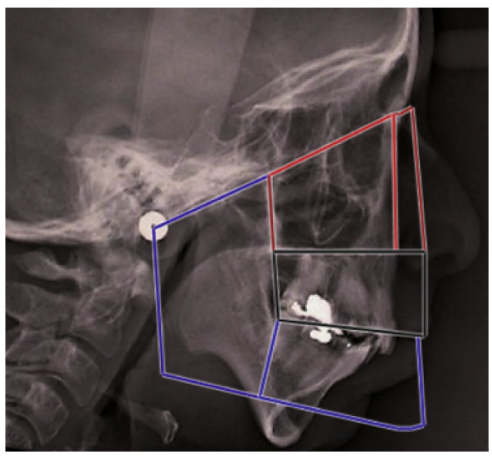

\begin{abstract}
RESUME
The morphological particularities of the posteriorly rotated mandible, first described by A. Björk, may correspond to extremely variable clinical situations. We can derive important information by analyzing the forms and proportions of different mandibular entities. This article proposes to illustrate the most frequently encountered situations by describing a number of cases of posterior rotation and by explaining how Delaire's architectural analysis can be used in clinical practice.
\end{abstract}

\section{KEYWORDS}

Mandible

Condyle

Posterior rotation

Growth.

Article received: 06-2010

Accepted for publication: 07-2010

\section{INTRODUCTION}

Mandibular rotations are widely known and frequently used in determining the prognosis of both vertical and posterior skeletal deviations. The typological characteristics of "posterior rotation," considering the 7 points that Björk ${ }^{2,3,4}$ initially described, orientation and shape of the mandibular condyles, shape of the mandibular symphysis, shape of the lower occipital border, orientation of the mandibular canal, and the proportion of the lower third of the face, can, nevertheless, refer to very different clinical situations.
In Class II division 1 malocclusions, signs of posterior rotation may reflect weak mandibular growth and, because of it, make the prognosis for effective functional therapy dim. But for certain types of Class III malocclusion similar signs may, on the other hand, accompany a strong growth potential and minimize the "real" interarch discrepancy.

According to Moss's 1968 work, cited by Latrou $^{9}$, the anatomic mandible is formed from the juxtaposition of several functional

Address for correspondence:

COHEN-LEVY,

255 rue Saint-Honoré,

75001 Paris,

France.

juliacohenlevy@wanadoo.fr 
entities, a systematic analysis of which such as the one proposed by Delaire and Salagnac, makes it possible for practitioners to create more precise diagnoses $5,6,7,13$. These improved formulations will be based on the size of the condyles, which depends on genetic influences and adaptive growth, the size of the coronoid processes, a function of the temporal periosteal matrix, the form and the shape of the gonial region, a function of the masseter and the medial ptyergoid matrix, with respect to the spinal column ${ }^{11,12}$ and, finally, the orientation of the alveolar processes.

This article will review different clinical situations described by a morphological analysis of the mandible and then by an orthognathic architectural construction using Delaire's digitized analysis (Tridim ${ }^{\mathrm{TM}}$ ). The results of the simplified analysis are presented in

\section{PRESENTATION OF CASE NUMBER ONE}

This 30 year-old patient suffers from a rare systemic disease, related to skin sclerosis, or scleroderma, called the stiff skin syndrome. Small in size, with deformed fingers she walked and seated herself with difficulty. Although the effort was not painful, she could open her mouth only to a limited extent making taking pictures of her teeth (fig. 1 a to g) a troublesome procedure.

The stiff skin syndrome is a genetically transmitted disorder that affects skin and connective tissue throughout the body that leads to progressive decrease in joint mobility, caused, an international team of researchers discovered last year, by excessive graph form with the maxillary area represented in the naso-maxillary stage in red, the dento-alveolar area in black and the mandible in blue. All are constructed with an ideal relationship to each subject's cranial and cervical morphology.

For the first case of a severe mandibular hyperdivergence, Professor Delaire, the eponymous creator of the analysis, himself has prepared a complete morphological study of the skeletal and pharyngeal structures that delineates the deformations and insufficiencies in the development of the different entities as well as the notion of auxological potential.

We discuss the repercussions such studies of the different types of posterior rotation of the mandible can have on orthodontic, orthopedic, and surgical therapy,

production of the protein fibrillin-1 and possibly transmitted by a dominant autosomic gene ${ }^{1,10}$.

\section{- An oral examination revealed:}

- lack of lip closure at rest

- a strongly convex facial profile

- a "gummy" smile

- and a reduced chin to neck distance

- The patient had a Class I molar occlusion, almost normal overjet as a result of orthodontic treatment accompanied by the extraction of both maxillary canines and two lower bicuspids and germectomy of all four third molars that she had undergone as a teenager. 

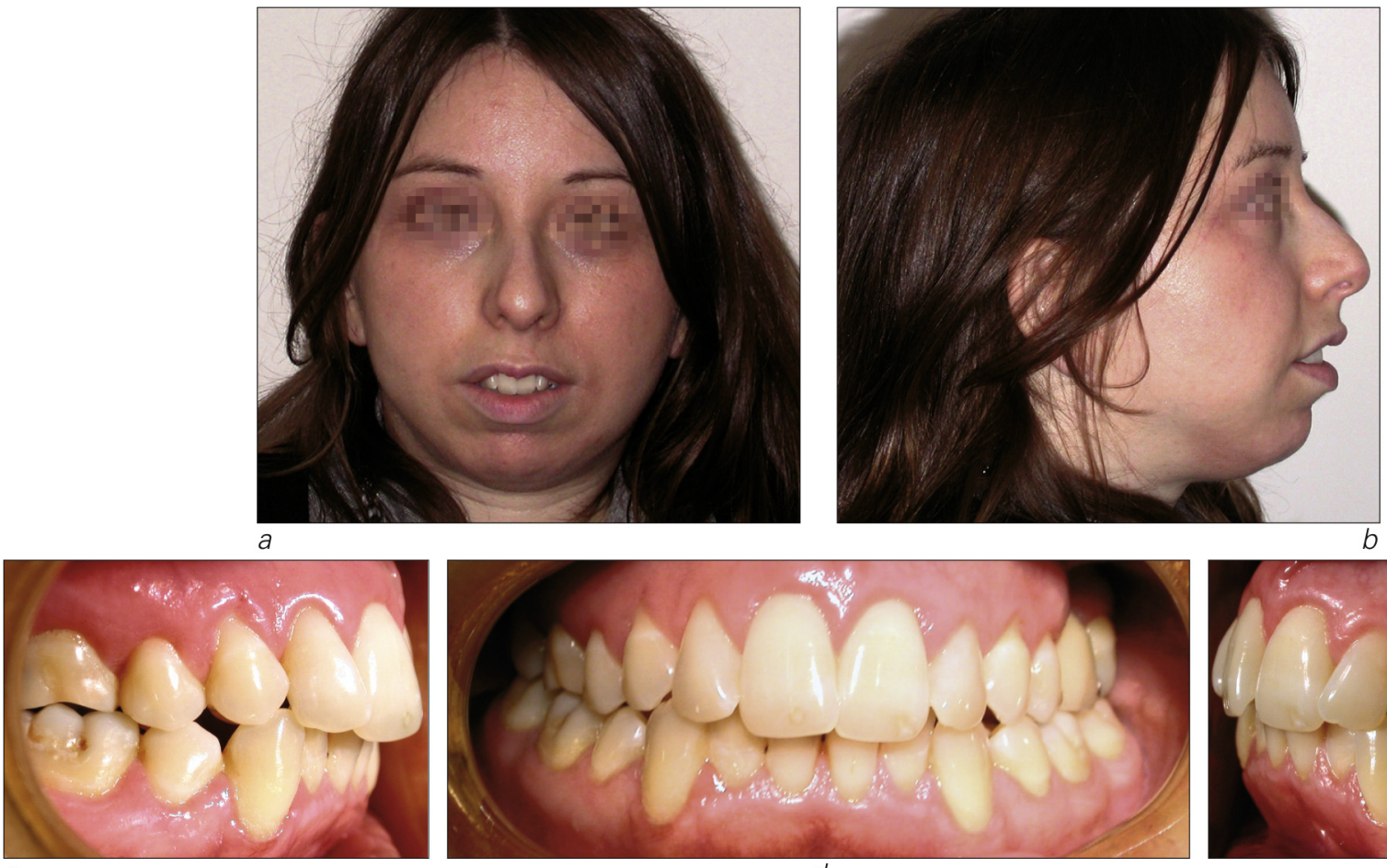

c
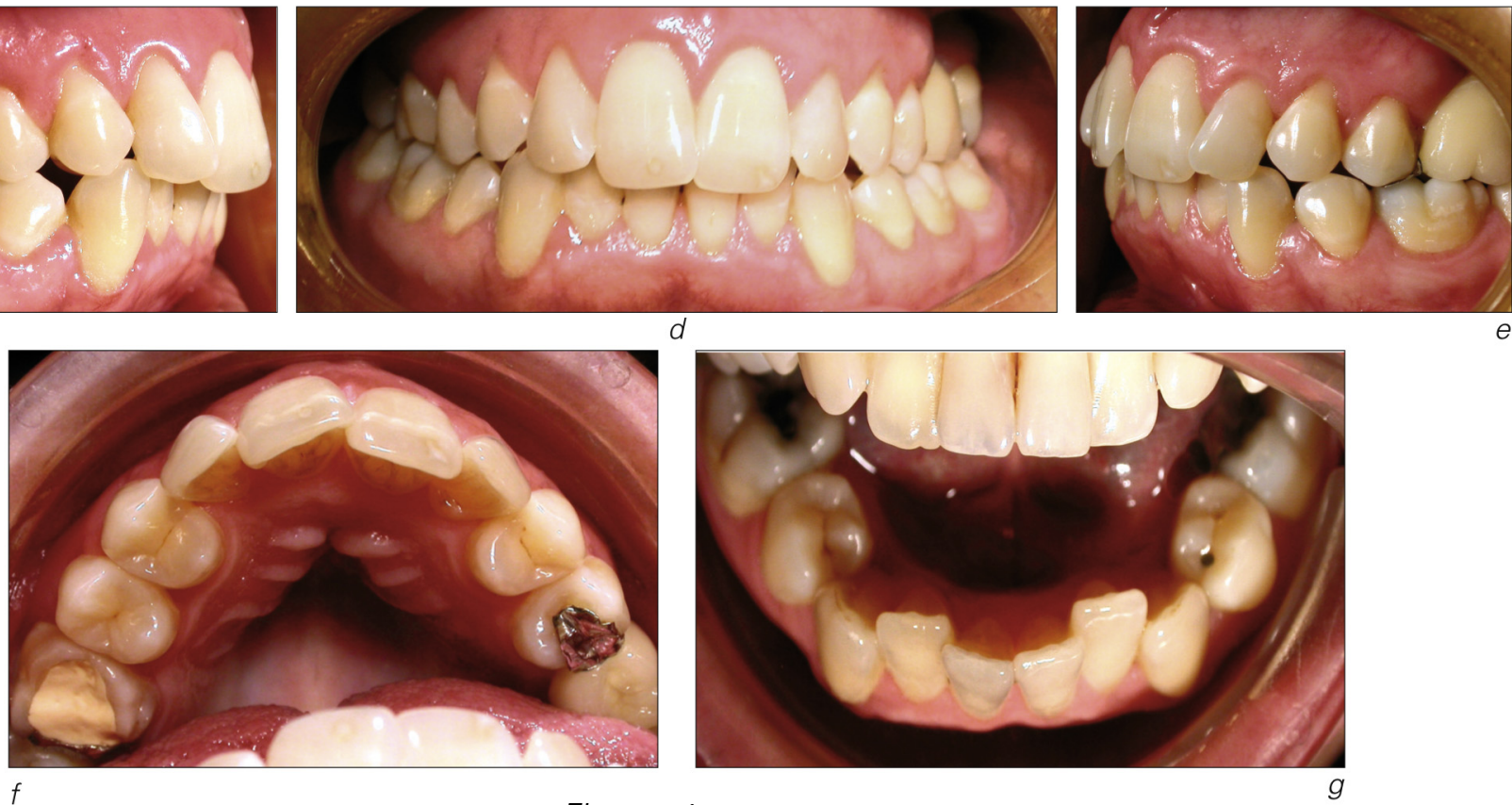

Figures 1 a to $g$

Facial and intraoral photographs of patient 1, who suffers from the stiff skin syndrome. Note her facial convexity and her inability to close her lips at rest. Her dental occlusion, however, was relatively well balanced.

\section{Analysis of the profile cephalometric X-ray}

- The head of the condyle is small, shorter than the coronoid process, and oriented obliquely backward. The posterior border of the ramus is concave and the angle of the mandible is positioned higher than
C2-C3 intervertebral disc, open to an exaggerated extent, and with a marked antegonial notch. The symphysis is high and extremely narrow in it upper sector.

- The apices of the molars are very close to the mandibular canal while the apices of the incisors are at a considerable distance from the border 
of the mandible. The occlusal plane is tilted vertically, which makes the patient's smile almost gummy

- In addition, one can note, a narrowing of the caliber of the airways that appear to be shrunken behind the base of the tongue. A partial calcification of the stylohyoid ligaments can also be seen.

- An architectural orthognathic analysis (shown in simplified form in fig. $1 \mathrm{i}$, and in complete form in fig. 1 j) gives a clear picture of the forward position of the condyle, posterior vertical insufficiency, anterior vertical excess, bi-maxillary retrusion with a short mandible as well as a Class II skeletal pattern. The analysis presented in figure $1 \mathrm{k}$ quantifies the developmental shortcomings of the skeletal components of the mandible, showing how it can be a formidable tool for planning surgical procedures. The tracing depicted in figure 1 I focuses on the pharyngeal airway.

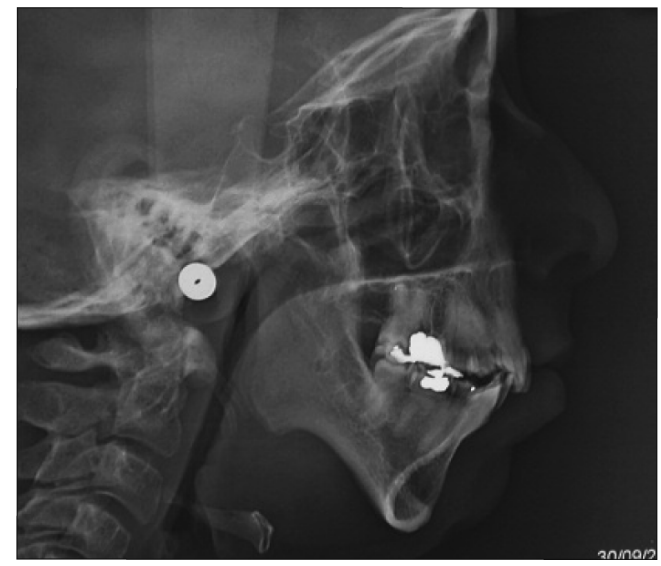

Figure $1 \mathrm{~h}$

Profile cephalometric film. Note the signs of marked posterior rotation, thin symphysis and pronounced antegonial notch.

\section{What diagnosis has been delineated?}

The shortness of the condyles was caused by an organic assault on the condylar blastema that provoked insufficient posterior vertical development, a posterior rotation of the body of the mandible, and, finally, repercussions affecting the teeth and the alveolar process. In addition to malformation syndromes like hemi-facial microsomia, the Treacher Collins or Goldenhar syndromes as well as inflammatory, infectious, and traumatic assaults on the condyles may be at the root of the problem.

While moderate cases that have little clinical effect do exist, other, more serious disorders may, in their development, express themselves in

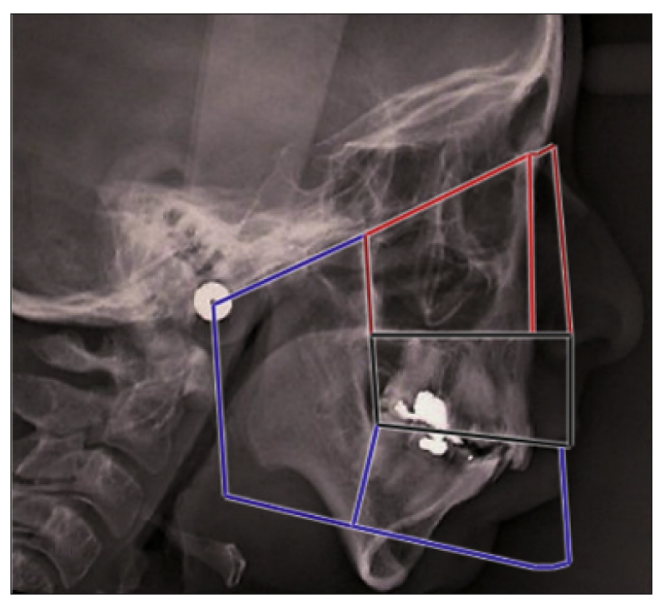

Figure $1 \mathrm{i}$

Simplified analysis with the ten most important traits portrayed. The ideal maxillary configuration is shown in black, and the ideal mandibular in blue in contrast to the actual cranial and cervical morphology of the patient. The maxillary and mandibular structures are clearly seen in their retro position in relation to the ideal framework. The ensemble of this patient's facial complex has rotated in a distinct counter-clockwise fashion. 

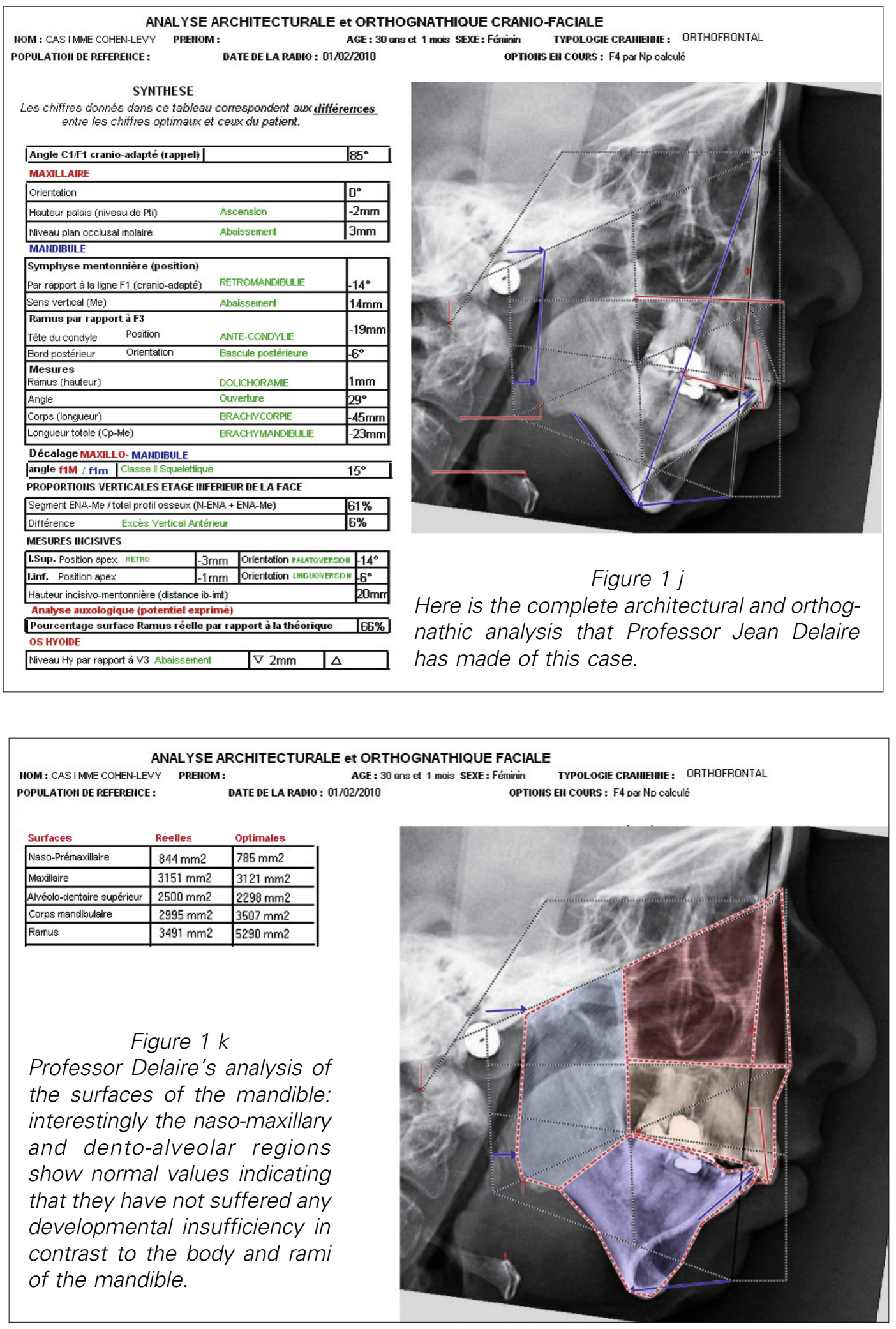


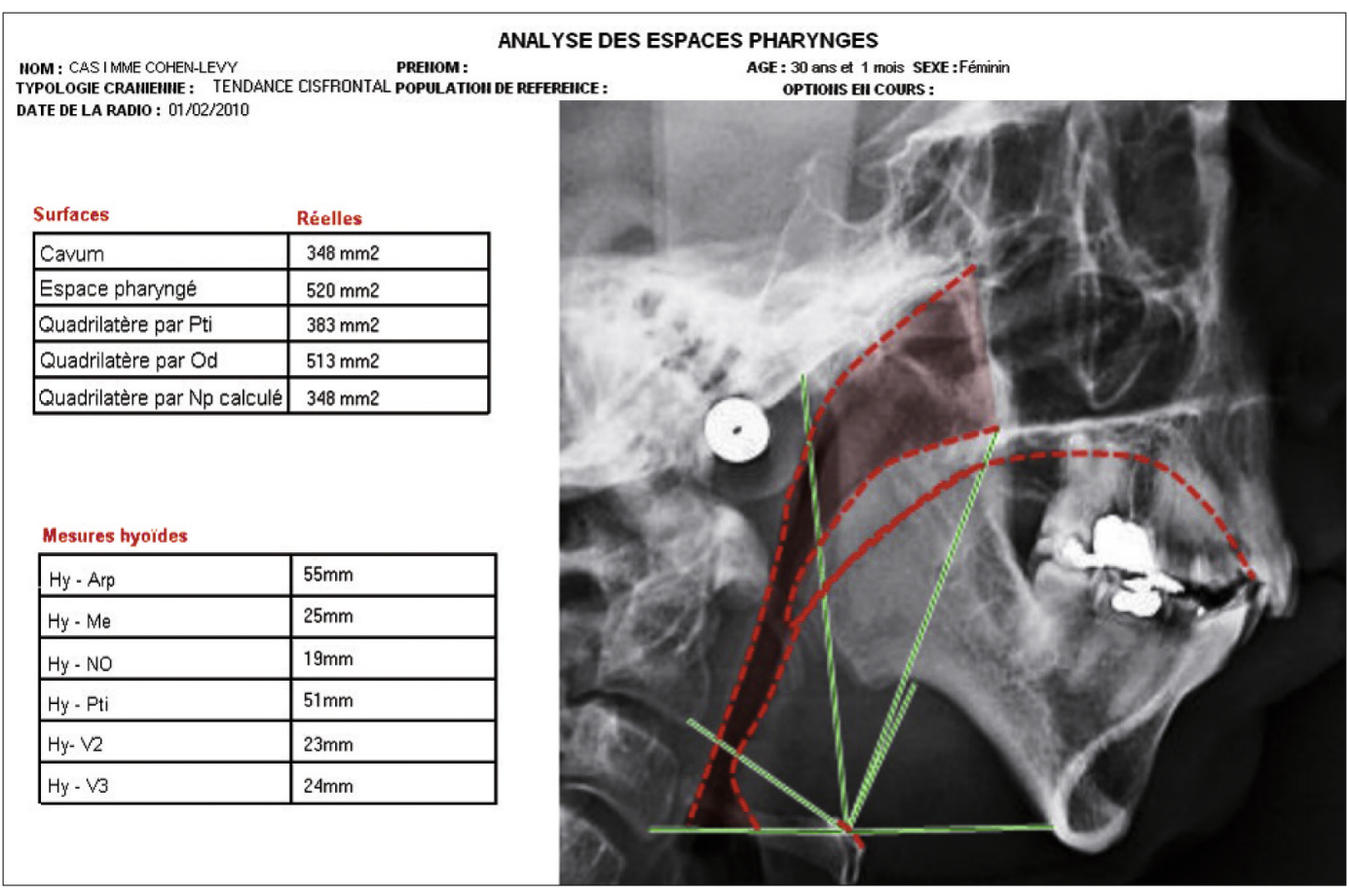

Figure 11

Professor Jean Delaire's analysis of the oro-pharyngeal soft tissues above the hyoid bone.

temporo-mandibular joint ankylosis, intra-articular hemorrhage, condylar fractures, prolonged immobilization of the mandible, systemic and local infections, scleroderma, and spondylarthritic ankylosis.

\section{What procedures should the practitioner initiate and what eventual influence will this type of posterior mandibular rotation have on orthodontic treatment?}

In cases of short rami, traditional orthognathic surgery could give disappointing results. The usual treatment consists of a sagittal osteotomy that corrects the antero-posterior discrepancy but perpetuates the intrinsic mandibular imbalance and gives the body of the mandible a relative excess of length from the work of Professor Ferri ${ }^{8}$ ).

In this particular case, because of the patient's serious systemic disease and in spite of the negative esthetic effects of the malocclusion, we did not plan any surgical intervention, not even a genioplasty, because, in the surgeon 's opinion, the difficulties of intubation and the risk of poor osseous consolidation would be too great.

On further examination we determined the patient was suffering from a moderate case of obstructive sleep apnea syndrome for which she had demonstrated no daytime symptoms. She was successfully treated for this disorder with non-invasive positive pressure ventilation. 


\section{PRESENTATION OF CASE NUMBER TWO}

Here are the basic diagnostic features of this case of a 12 year-old female patient suffering from Still's disease, juvenile rheumatoid polyarthritis.

\section{- Occlusion:}

- asymmetric Class II division 1 malocclusion,

- a narrow maxillary arch with a cross bite of the right buccal teeth,

- all four first molars had been extracted because of rampant caries,

- anterior overjet of $5 \mathrm{~mm}$. In anterior propulsion patient slid her mandible $2 \mathrm{~mm}$ away from centric relation.

- Basal bone was in a Class II relationship with a retruded mandible and hyperdivergent face.

\section{- Treatment}

Because of condylar resorption we consulted Professor Couly's maxillofacial surgery service at the Necker Sick Children University Hospital Centre, which graciously agreed to take care of the patient's medical needs.

With the approval of our consultants, we began a phase of orthopedic treatment with a monobloc activator. We concluded with a full banded and bonded 30 month treatment, accompanied by high pull head gear, to close spaces, coordinate the arches, and to obtain a Class I occlusion (see fig. 2 a to $h$, before treatment, and fig. 2 I to $p$, after treatment).

\section{- At a check-up visit ten years after} the end of treatment we found that the occlusion had relapsed to a Class II relation, the patient's profile was retrusive, and that a molar-to-molar open bite had appeared. (fig. $q$ to $x$ ).
- An architectural analysis before treatment delineated the inadequate vertical development of the rami before treatment (fig. 2 y), the maxillary retrusion, and the continuation of the posterior rotation of the mandible, with a marked ascension of the mandibular angle during the course of treatment that continued until the end of the growth period (fig $2 \mathrm{z}$ to $\mathrm{z}^{\prime}$ ).

\section{What diagnosis has been delineated?}

Rheumatoid polyarthritis is a chronic inflammatory disease that causes progressive destruction of joints and imposes multiple and, sometimes, profound functional, psychological, social, and, later, professional problems on patients it strikes. It is the most frequently occurring and the most severe of the inflammatory rheumatoid diseases, affecting 0.3 to $0.5 \%$ of the French population. The disease develops in spurts separated by periods of remission. During the acute phases, joints become swollen and painful and patients suffer from moderate fever and asthenia. When attacks by the disease on both left and right temporo-mandibular joints become aggravated they can cause deformities and a crippling destruction of the heads of the condyles.

In this young patient's case, the early destructive effect on the heads of the condyles diminished the height of the rami so that gonion rises in relation to the lower border of the odontoid process. This also generates an imbalance of the maxillo-facial 

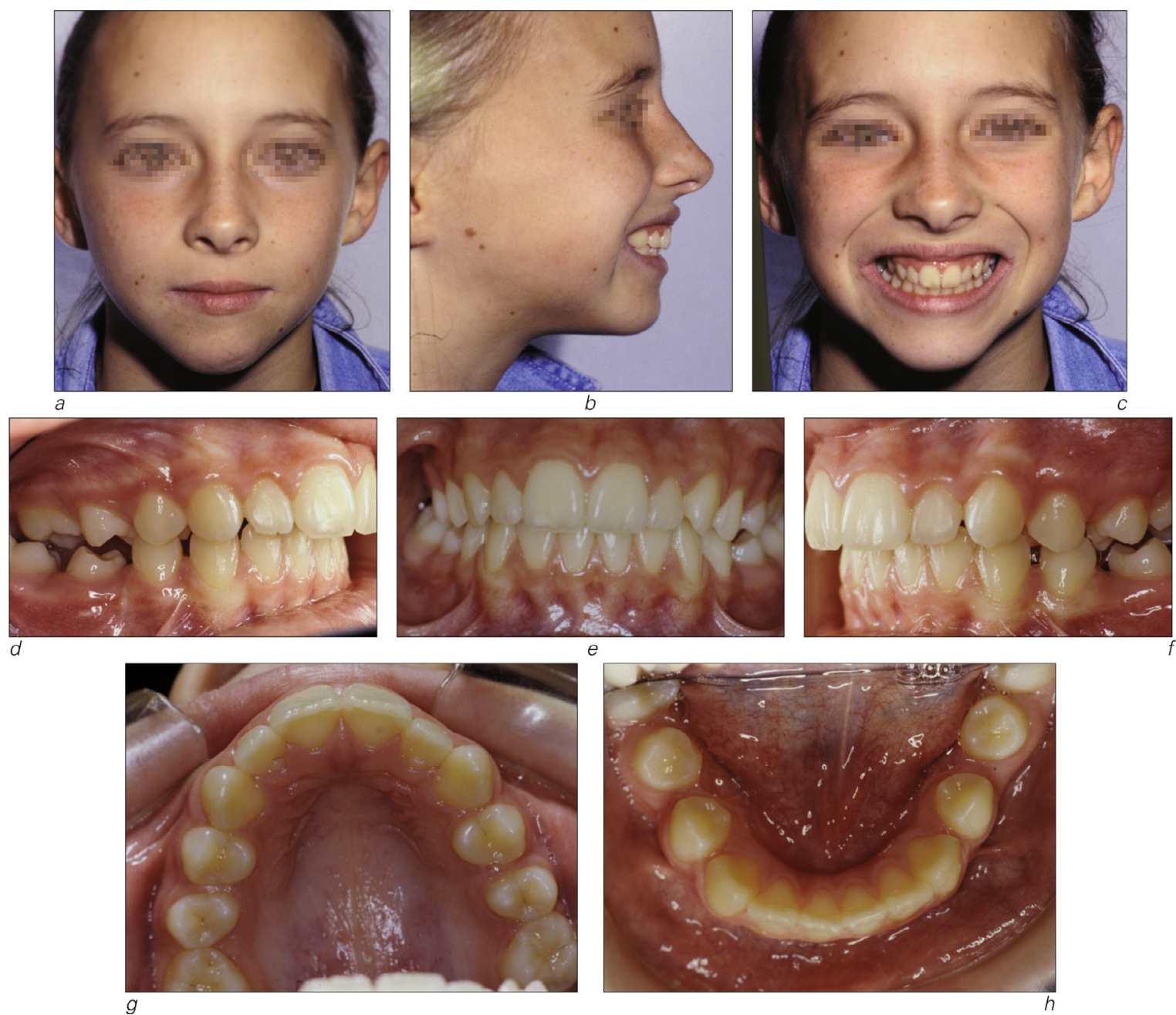

Figures 2 a to $h$

Facial and intraoral photographs of patient 2, who is afflicted with rheumatoid polyarthritis before treatment.

complex within its framework, markedly verticalizing the occlusal plane.

\section{What procedures should the practitioner initiate and what eventual influence will this type of posterior mandibular rotation have on orthodontic treatment?}

This kind of severe relapse can bewilder the orthodontist, especially after such a therapeutic success, which, even more gratifyingly, had been achieved after the end of the pubertal growth spurt.

The brutal appearance of the anterior open bite reflected a progression of the rheumatoid polyarthritis's disintegrating action on the heads of the condyles, although the persistence of juvenile swallowing may have made a functional contribution to the onset of this unwelcome occlusal development. 


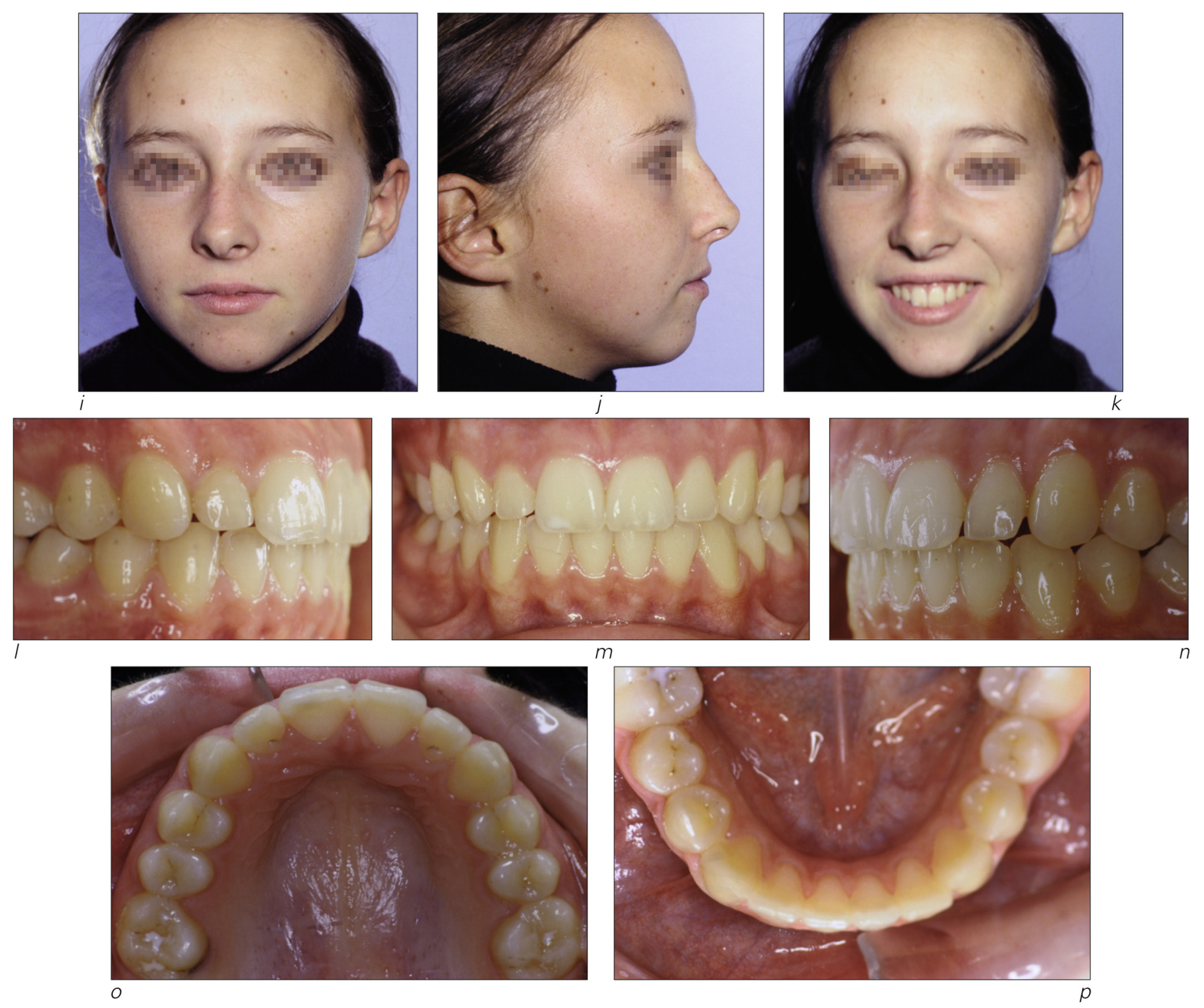

Figure 2 i to $p$

The same patient after treatment. Note the harmonious smile, the well-balanced profile, with overjet and overbite within normal limits.

As a component of our plan to treat this problem symptomatically, we do not plan to grind the posterior inter-arch contacts that protect the joints, but, instead to construct a thin oral splint that would increase vertical dimension only slightly but would have the effect of augmenting the distribution of the inter-arch contacts.

The increasing severity of the patient's arthritic disease would make it 


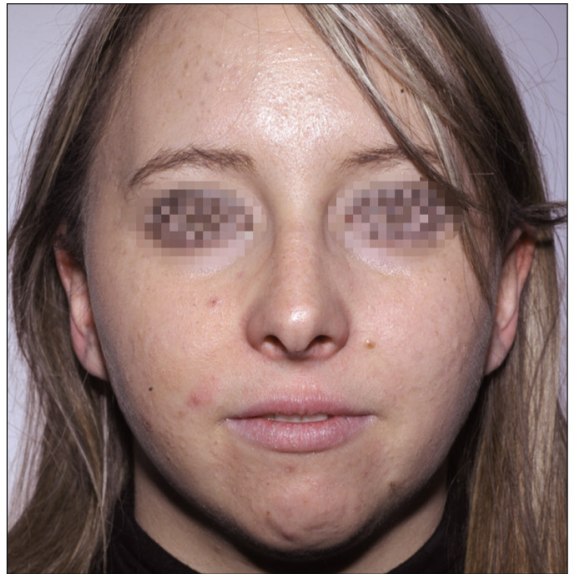

q

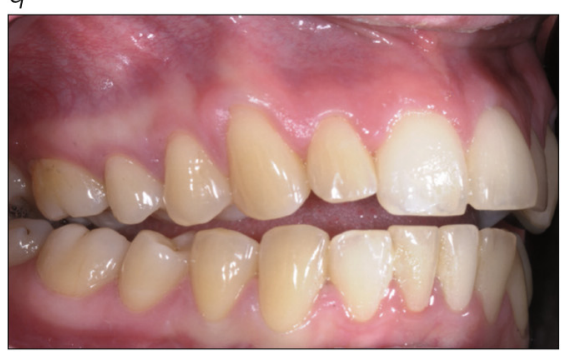

$t$

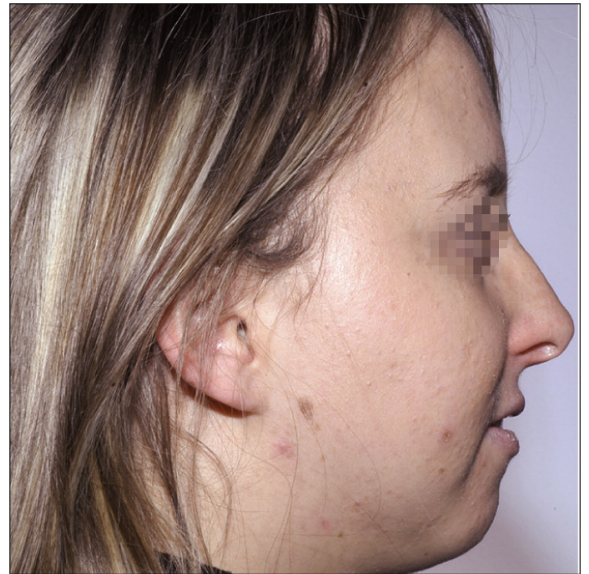

$r$

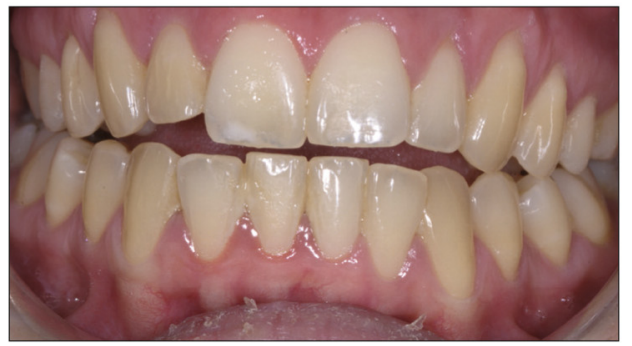

u

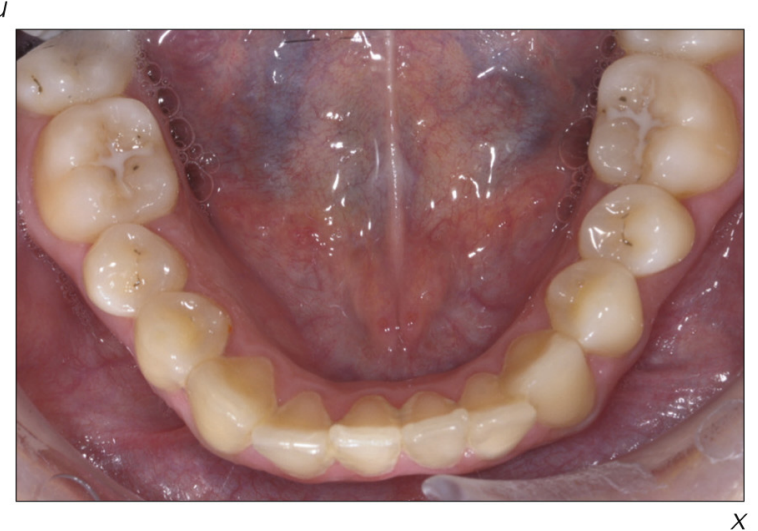

Figures 2 q to $x$

Facial and, especially, intraoral photos of the same patient ten years after the end of treatment show the brutal appearance of an open bite that extends from molar to molar associated with a retrusion of menton.

difficult to justify correcting the new Class II relationship and the open bite with a mandibular osteotomy but we may consider a genioplasty at some future time to bring the maxilla to mandible relationship and the unaesthetic "chinless" profile closer to normal limits. 


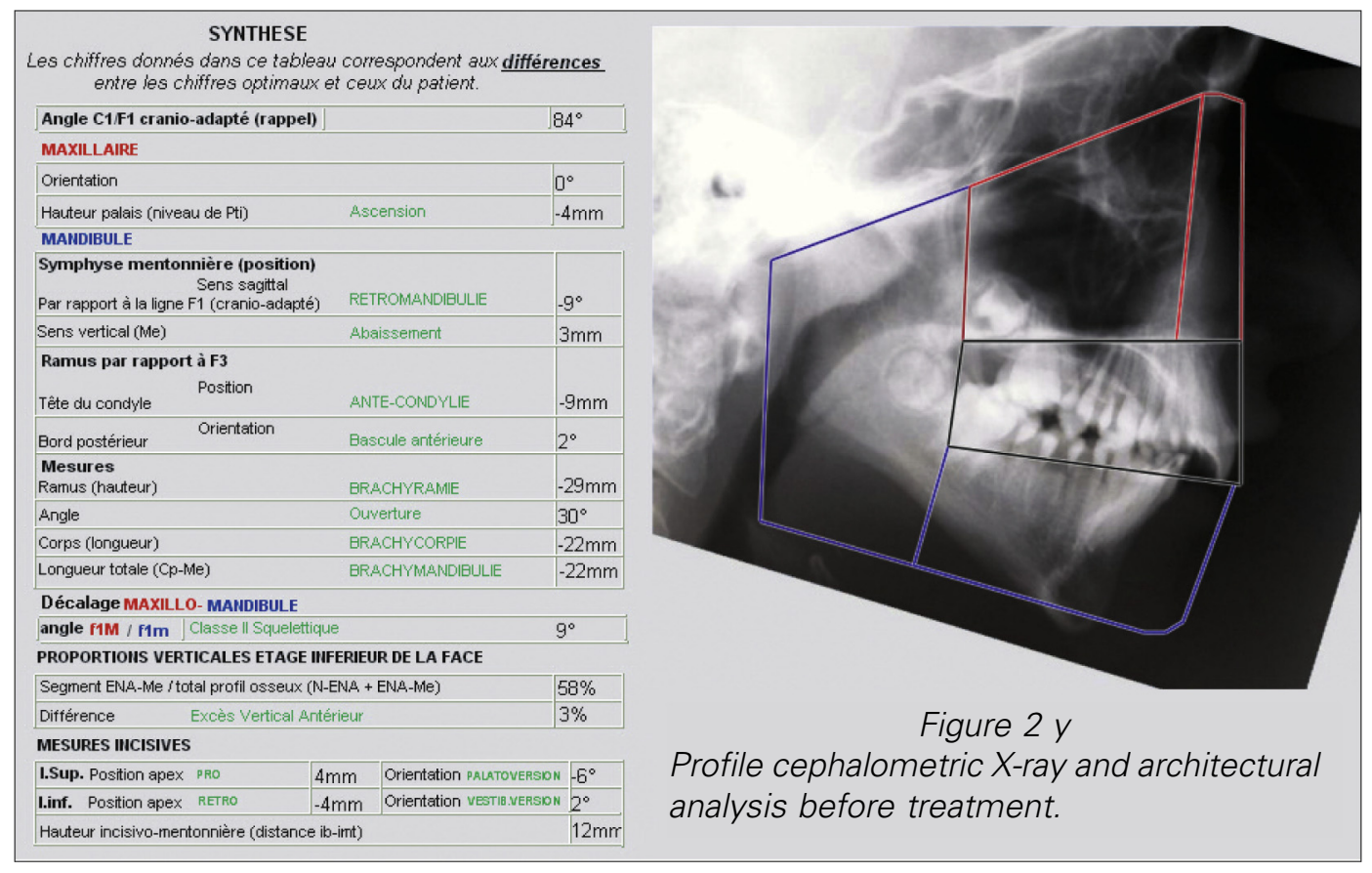

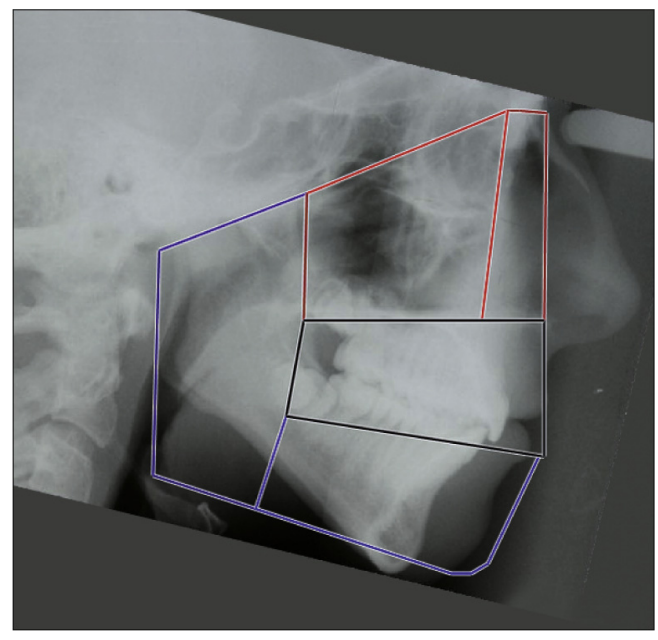

Figure $2 z$

Profile cephalometric $X$-ray at the end of treatment and simplified architectural analysis.

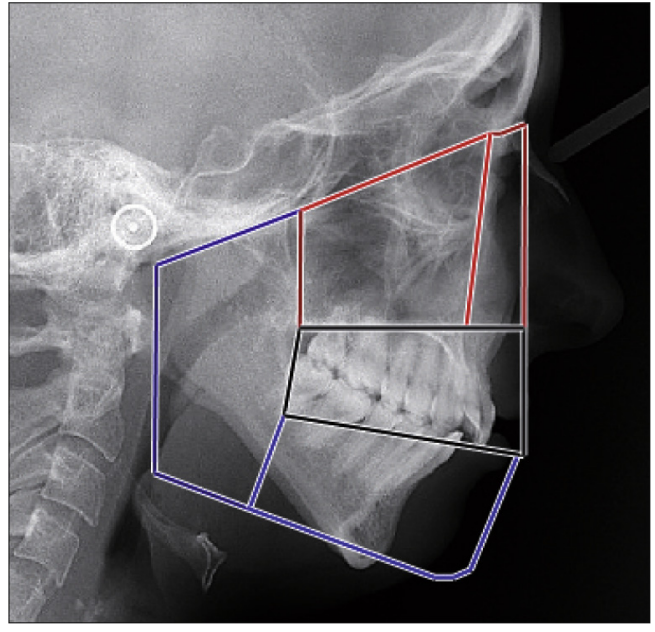

Figure $2 z^{\prime}$

Profile cephalometric $X$-ray taken at the end of growth period recall visit. 


\section{PRESENTATION OF CASE NUMBER THREE}

This 8 year-old girl consulted us because of the delayed eruption of her upper lateral incisors as well as the upper first molars that were blocked under the second temporary molars. (fig. 3 a to g). Even though her tonsillar tissues were hypertrophied she displayed no symptoms of otolaryngological infection or serious otitis.

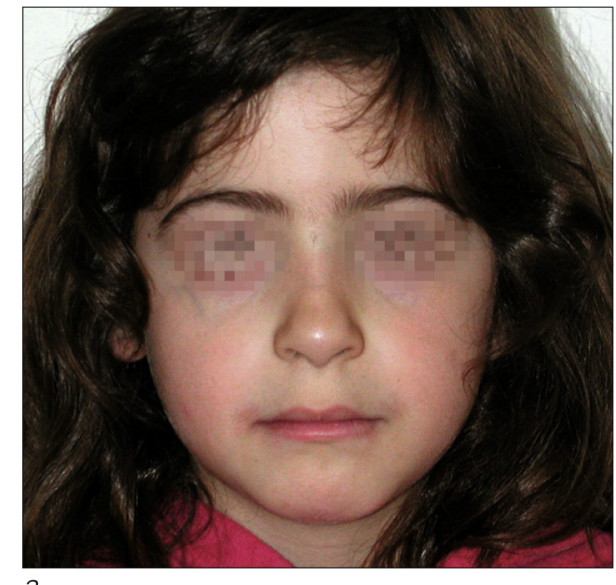

a

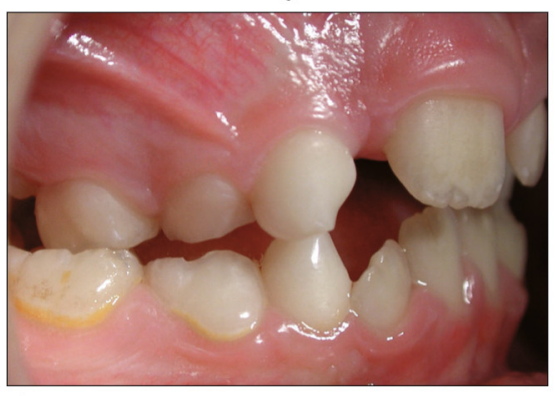

C

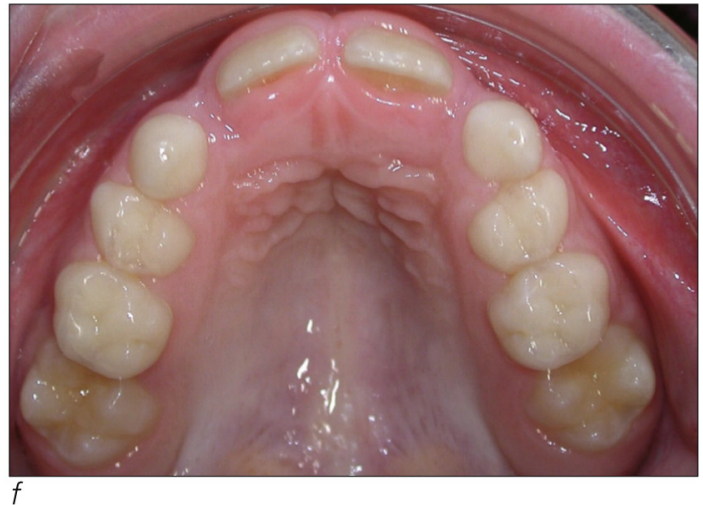

Figure 3 a to $g$

d
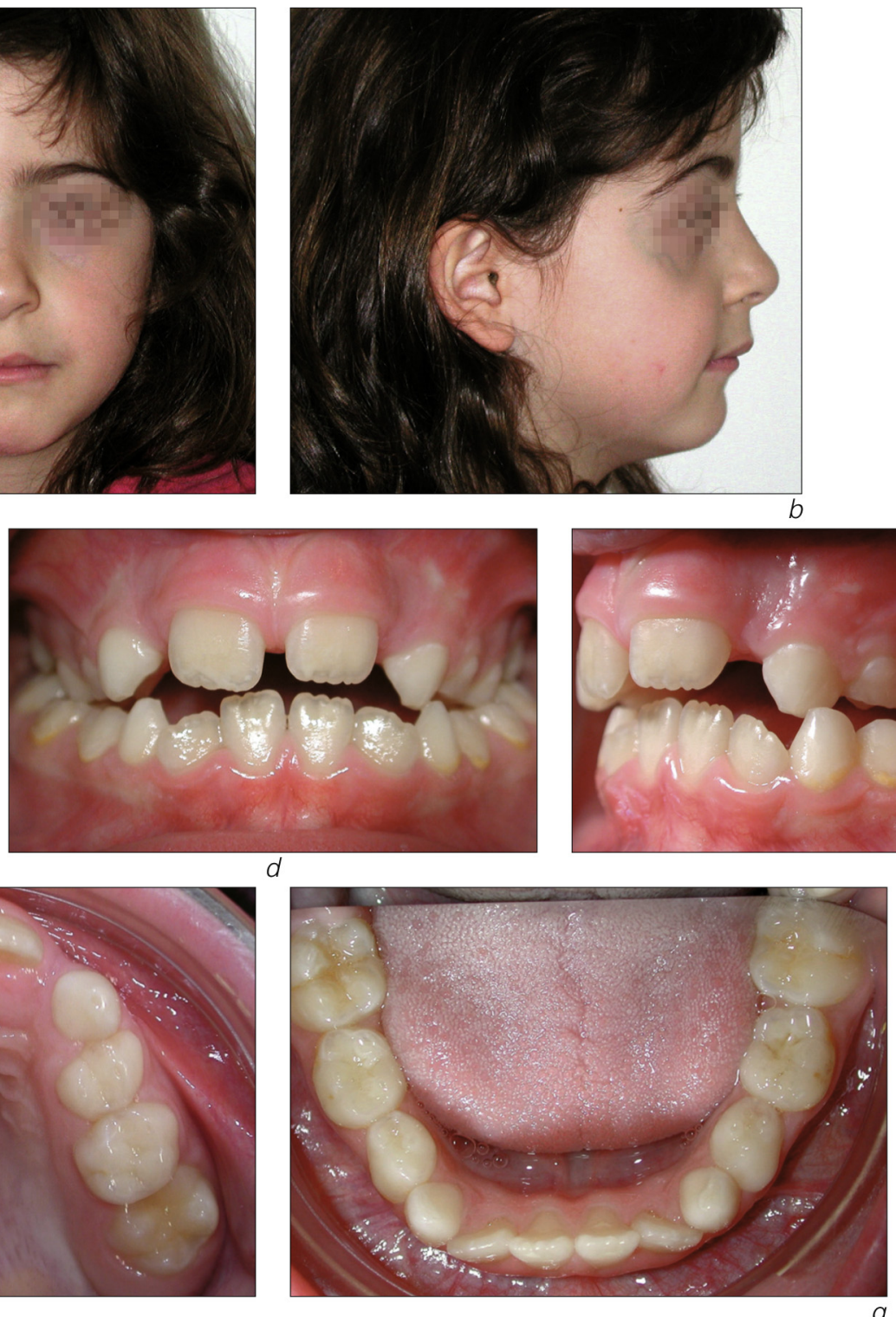

g

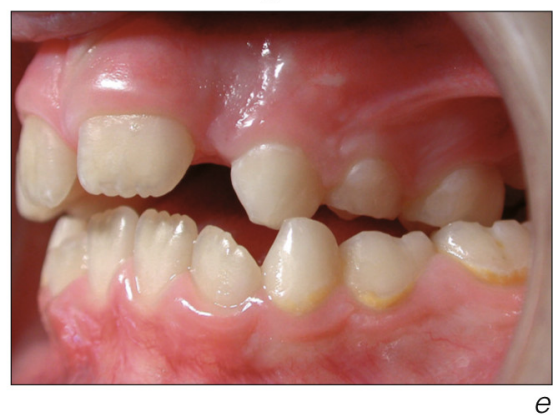

e

Facial and intraoral photos of patient 3 who suffers from juvenile obstructive sleep apnea syndrome. She had a Class II malocclusion, a narrow and retruded maxilla, with bilateral buccal cross bites, and an anterior open bite. 
Analysis of the profile cephalometric X-ray (fig. $3 \mathrm{~h}$ )

- Hypertrophied adenoidal tissue with a narrowing of the retro-alveolar airway can be seen.

- The head of the condyle is diminished in size and is at the same level as the upper edge of the coronoid process. The posterior borders of the rami are slightly concave and the body and rami are short.

- The mandibular angle is ascending and rather open with a marked antegonial notch

- The symphysis seems to be smaller than normal size.

- An orthognathic analysis of the profile head films reveals bi-maxillary retrusion, insufficient vertical

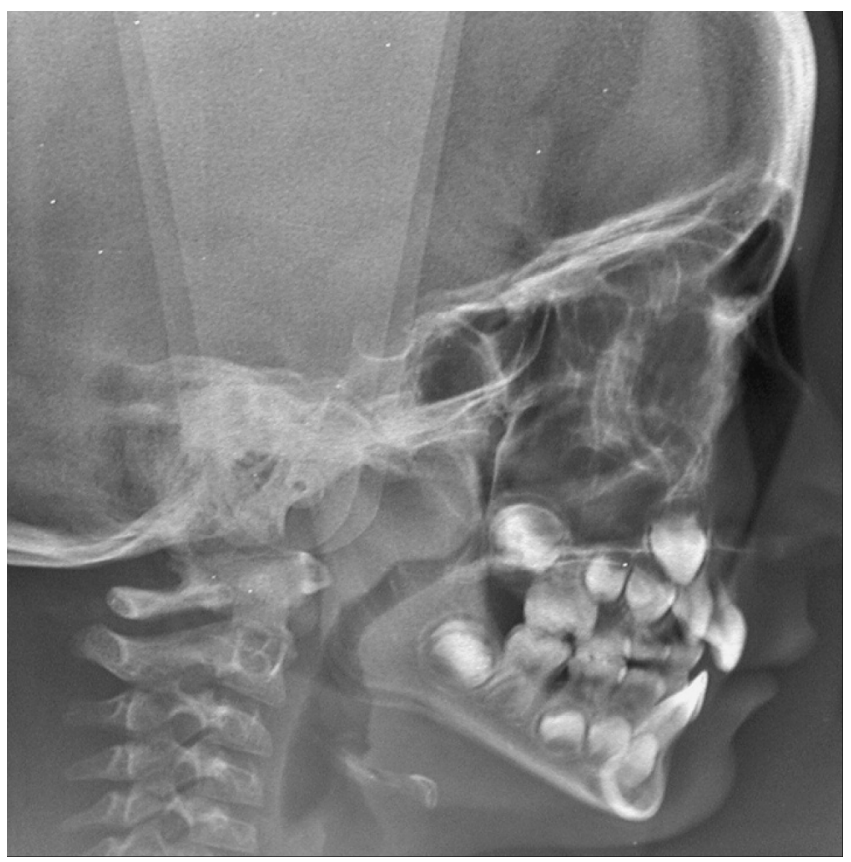

Figure $3 \mathrm{~h}$

Profile cephalometric film shows adenoid and tonsillar hypertrophy. The maxillary first molars are in a mesial position. and horizontal development of the mandible causing both the body and the rami to be shorter than normal (fig. 3 i).

\section{What diagnosis}

\section{has been delineated?}

In this case of micro, or small mandible, development of all components has been altered with the exception of the dento-alveolar sector. The lower arch is well developed, without crowding. The narrow maxilla is retruded and the upper teeth are in bi-lateral cross bite, which may be related to the patient's habitually keeping his tongue in a low position and being a mouth breather.

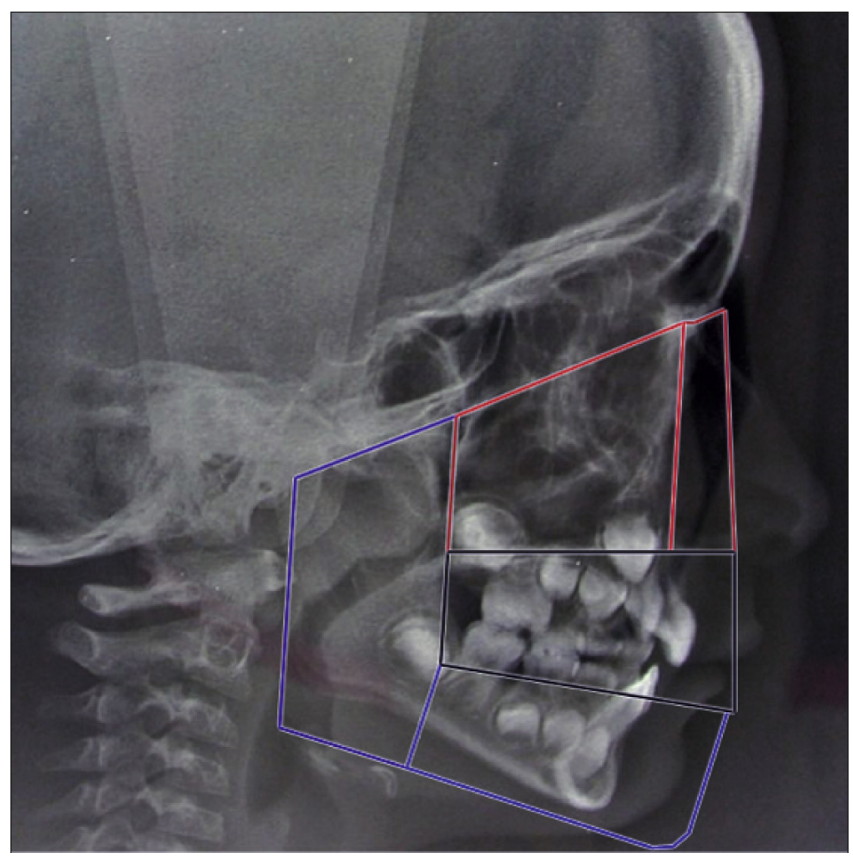

Figure $3 i$

Simplified architectural analysis shows bi-maxillary retrusion. The mandible's vertical and horizontal dimensions of both the corps and the rami are below average. 
What procedures should the practitioner initiate and what eventual influence will this type of posterior mandibular rotation have on orthodontic treatment?

Because of the patient's facial retrusion and young age, we decided to attempt to stimulate growth with orthopedic procedures and to avoid extractions.

After an orthodontic evaluation, we requested a polysomnographic examination. It confirmed what our assessment had indicated, that the patient

\section{PRESENTATION OF CASE NUMBER FOUR}

Surgeons had operated on this seventeen year-old boy numerous times to correct his left labio-alveolarpalatal cleft by closing the oro-nasal opening, performing a uni-lateral $\mathbf{Z}$ labioplasty, and bringing the upper left cuspid into its place in the arch with surgico-orthodontic means. His upper left lateral incisor was congenitally absent.

The esthetic repercussions of his deformity, which were profound, were caused by lack of support for his nose and insufficient lateral growth of the maxilla (fig. 4 a to $\mathrm{g}$ ).

Because of the narrow and retruded upper arch, there was a bilateral cross bite of the buccal teeth. A severe anterior open bite was present together with asymmetry caused jointly by the maxillary midline's drifting to the left toward the space of the missing lateral incisor and by the lateral deviation of the mandible. suffered from a severe case of obstructive sleep apnea syndrome with peaks of oxygen desaturation. After we began to treat her with rapid palatal expansion, the index of apnea-hypopnea spontaneously improved making a tonsillectomy and adenoidectomy less urgent.

Later, treatment with an activator may be indicated to stimulate growth of the mandible, whose vertical growth, despite the anterior open bite, was inadequate, probably because of the tongue's habitual low and forward positioning.

\section{Analysis of the profile cephalometric X-ray (fig. $4 \mathrm{~h}$ )}

- The head of the condyle is quite large with a long and thick neck resembling the coronoid process, which is also over-developed.

- The angle of the mandible is split, lowered on one side, and extremely open, with a well-chiseled antegonial notch.

- The mandibular symphysis is rather delicate, with the lower dental arch seemingly retruded as a compensation for the Class III malocclusion.

- Paralleling these features tongue posture is low, maxillary structure seems to have collapsed with the pre-maxilla rising as a component of an exaggerated compensatory curve.

- An orthognathic analysis reveals a skeletal Class III conformation 

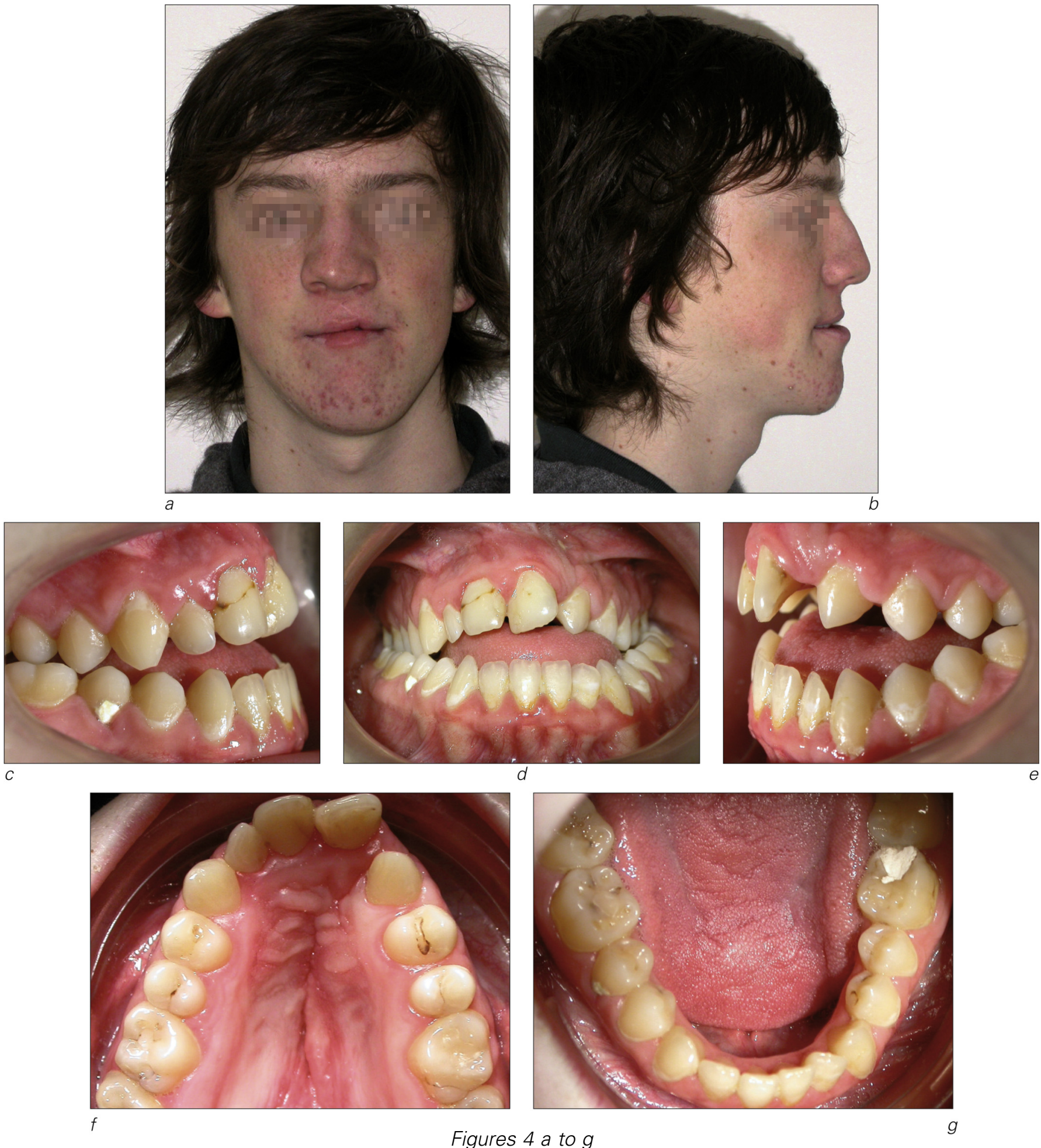

Figures 4 a to $g$

9

Facial and intraoral photographs of patient 4 who had received treatment for a naso-labio-alveolar-palatal cleft. He had a Class III malocclusion with insufficient lateral growth of the maxilla. 


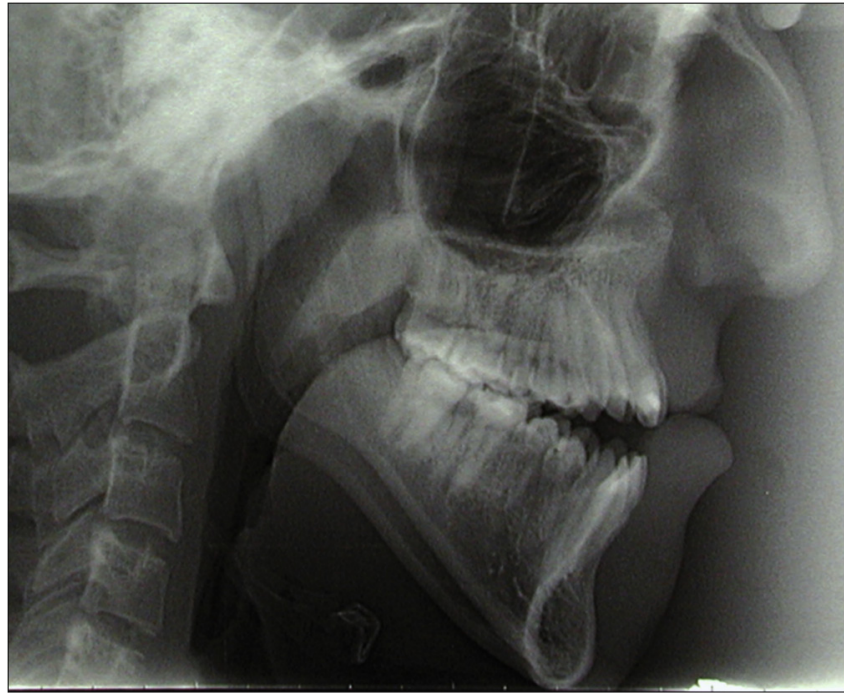

Figure $4 \mathrm{~h}$

The mandible is long and massive and shows marked signs of posterior rotation.

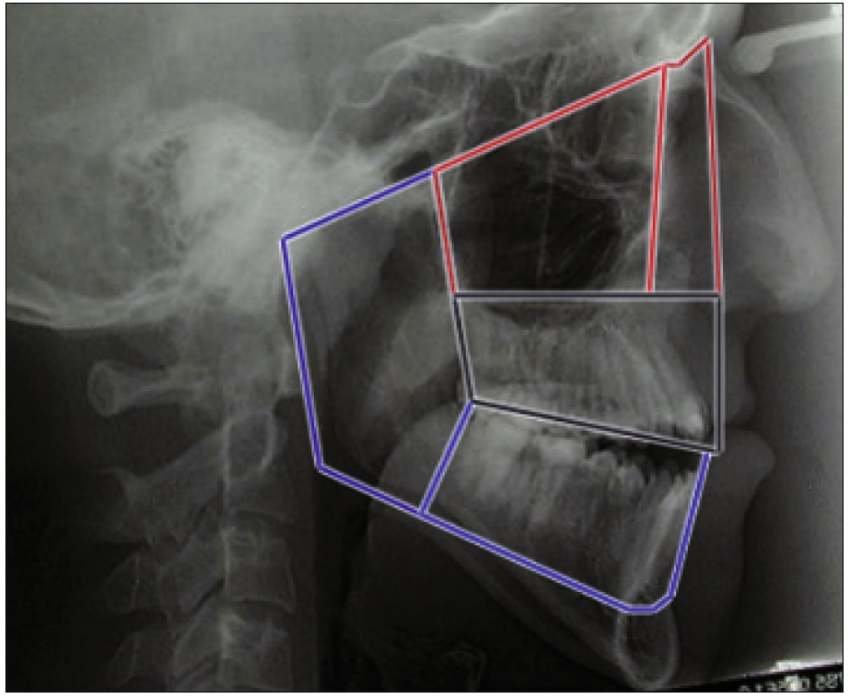

Figure $4 i$

This simplified architectural analysis shows the excessively long body of this mandible that extends vertically beyond the "ideal" framework but whose rami seem to conform better to the standard dimensions. The underdeveloped maxilla has an ascending anterior portion.

The architectural analysis reveals that this patient does not have a true macro-mandible but, instead, anteriorly placed condyles in addition to an excessively long mandibular body or dolicho mandible.

\section{What diagnosis has been delineated?}

Macro-mandibles, which show increase of substance in all three dimensions of space, are rare anomalies, notably found in cases of acromegaly. They exhibit very strong condylar growth, a phenomenon that often generates a Class III mal-occlusion that is likely to be asymmetrical. The lowering of the mandibular angle toward the second cervical vertebra $(\mathrm{C}$ 2) reflects excess of posterior vertical height, a finding that does not seem to obtain in this particular case.

\section{What procedures should the practitioner initiate and what eventual influence will this type of posterior mandibular rotation have on orthodontic treatment?}

In cases of true hypercondylia, a single or bilateral condylectomy is strongly indicated. On the other hand, when the mandibular angle is located above the C 2 vertebra, this is usually a sign of vertical posterior insufficiency. 


\section{CONCLUSION}

Like cats, all images of posterior rotation may look gray in the dark, but after a careful morphological analysis, effectively completed by an architectural construction, mandibles all have their own specific characteristics and the orthodontic, orthopedic, and surgical therapeutics for treating posterior rotation are numerous.
We invite our readers to intensify their understanding of the subject by reading the principal works of Professors Jean Delaire, Mercier, and Salagnac, whose studies have been the primary inspiration for these lines.

\section{REFERENCES}

1. Azevedo VF, Serafini SZ, Werner B, Müller CS, Franchini CF, Morais RL. Stiff skin syndrome versus scleroderma: a report of two cases. Clin Rheumatol. 2009 Sep;28(9):1107-1111. Epub 2009 May 5.

2. Björk A. Variation in the growth pattern of the human mandible. A longitudinal radiograph study by the implant method. J Dent Res 1963;42:400-411.

3. Björk A. Prediction of mandibular growth rotation. Am J Orthod 1969;55:585-599.

4. Björk A. Croissance mandibulaire normale et pathologique. Synthèse d'études céphalométriques longitudinales à l'aide d'implants sur une période de 25 ans. Rev Orthop Dento Faciale 1981;18:9-63.

5. Delaire J. L'analyse architecturale et structurale craniofaciale. Principes théoriques. Quelques exemples d'emploi en chirurgie maxillo-faciale. Rev Stomatol 1978;79:1-33.

6. Delaire J. L'équilibre architectural craniofacial en ODF et en chirurgie orthognathique. Orthod Fr 1985;85:353-364.

7. Delaire J. Le rôle du condyle dans la croissance de la mâchoire inférieure et dans I'équilibre de la face. Rev Chir Maxillofac 1990;91:179-192.

8. Ferri J, Movaghar R, Movaghar AS. Les insuffisances verticales postérieures de la mandibule : présentation d'une nouvelle technique de correction et étude rétrospective de 15 cas. Int Orthod 2007;5:98-110.

9. Lautrou A. Croissance faciale : théories explicatives et clinique orthodontique. Rev Orthop Dento Faciale 1994;28:433-453.

10. Liu T, McCalmont TH, Frieden IJ, Williams ML, Connolly MK, Gilliam AE. The stiff skin syndrome: case series, differential diagnosis of the stiff skin phenotype, and review of the literature. Arch Dermatol 2008 Oct;144(10):1351-1359.

11. Mercier J. L'intérêt de l'étude des rapports mandibulo-rachidiens dans l'indication opératoire en chirurgie orthognathique. Rev Orthop Dento Faciale 2007:41:461-477.

12. Mercier J, Gordeeff A, Delaire J. Les altérations de la dimension verticale postérieure de la face. Facteurs étiopathogéniques, critères architecturaux et aspects thérapeutiques. Orthod Fr 1989;60 Pt 2:575-582.

13. Salagnac JM, Delaire J, Mercier J. Développement vertical de la face et du rachis cervical. Intérêts diagnostique et thérapeutique en ODF et en chirurgie maxillo-faciale. Rev Stomatol Chir Maxillofac 1999;100:13-26. 